\title{
Factors affecting postoperative mortality of patients with insufficient union following osteoporotic vertebral fractures and impact of preoperative serum albumin on mortality
}

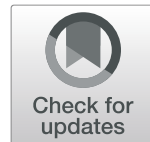

Tetsuro Ohba ${ }^{1 *}$, Hiroshi Yokomichi ${ }^{2}$, Kensuke Koyama ${ }^{1}$, Nobuki Tanaka ${ }^{1}$, Kotaro Oda ${ }^{1}$ and Hirotaka Haro ${ }^{1}$

\begin{abstract}
Abtsract
Background: Numerous comparative studies of surgical procedures have focused on clinical and radiographical outcomes, as well as the effect of bone fragility on the outcome of spinal surgery; however, insights concerning a risk of mortality or morbidity have been limited. Additionally, the effect of surgical therapy on survival after vertebral compression fractures remains controversial. Our aim was to evaluate the preoperative factors that affected the long-term survival of patients who underwent spinal surgery for an insufficient union following osteoporotic vertebral fractures (OVF) and to determine postoperative mortality.

Methods: We retrospectively reviewed the cases of 105 consecutive patients who underwent spinal surgery for OVF. Mortality was estimated using the Kaplan-Meier method and a log-rank test. The preoperative backgrounds of patients were analyzed to determine which risk factors led to death among the OVF cases. Kaplan-Meier curves were used to estimate survival based on preoperative albumin levels of $\leq 3.5 \mathrm{~g} / \mathrm{dL}$ (hypoalbuminemia) versus $>3.5 \mathrm{mg} / \mathrm{dL}$.

Results: The mean follow-up time was $4.1 \pm 0.8$ years. Two years after surgery, percentage of patients who had died was $15 \%$. The VAS scores and modified Frankel classification were significantly improved one year after surgery. The ratio of male-to-female was significantly higher for patients with OVF who died than for those who were still alive. No significant difference in mortality was observed among surgical procedures for OVF. The univariate analysis showed that male gender, serum albumin $<3.5 \mathrm{~g} / \mathrm{dl}$, creatinine clearance $<60 \mathrm{mg} / \mathrm{dl}$, and the American Society of Anesthesiologists classificat0ion $\geq 3$ were significant risk factors for postoperative mortality. Multivariate analysis revealed that only serum albumin $\leq 3.5 \mathrm{~g} / \mathrm{dL}$ was a significant risk factor for long-term postoperative mortality of patients with OVF.
\end{abstract}

Conclusions: Preoperative hypoalbuminemia was associated with postoperative mortality following surgery for OVF. Level of evidence: Level 3.

Keywords: Osteoporotic vertebral fractures, Mortality, Serum albumin

\footnotetext{
* Correspondence: tooba@yamanashi.ac.jp

'Department of Orthopaedic Surgery, University of Yamanashi, 1110 Shimokato, Chuo, Yamanashi 409-3898, Japan

Full list of author information is available at the end of the article
}

(C) The Author(s). 2020 Open Access This article is licensed under a Creative Commons Attribution 4.0 International License, which permits use, sharing, adaptation, distribution and reproduction in any medium or format, as long as you give appropriate credit to the original author(s) and the source, provide a link to the Creative Commons licence, and indicate if changes were made. The images or other third party material in this article are included in the article's Creative Commons licence, unless indicated otherwise in a credit line to the material. If material is not included in the article's Creative Commons licence and your intended use is not permitted by statutory regulation or exceeds the permitted use, you will need to obtain permission directly from the copyright holder. To view a copy of this licence, visit http://creativecommons.org/licenses/by/4.0/. The Creative Commons Public Domain Dedication waiver (http://creativecommons.org/publicdomain/zero/1.0/) applies to the data made available in this article, unless otherwise stated in a credit line to the data. 


\section{Background}

Osteoporotic vertebral fractures (OVF) are the most common type of fragility fractures, and they have become more prevalent as the proportion of the population that is older continues to increase [1]. Reports indicate that OVF increase overall mortality $[2,3]$. Conventionally, OVF are viewed as benign and treated with conservative methods such as rest, immobilization, drugs, and bracing [4]. However, vertebral fractures sometimes fail to unite, resulting in progressive kyphosis due to vertebral collapse and/or pseudarthrosis. Affected patients often endure persistent back pain and/or neurological deficits [5]. Despite conservative treatment, the prevalence of an insufficient bone union among elderly patients with OVF reportedly ranges from 10.0 to $13.5 \%$. The quality of life and activities of daily living of these patients may be reduced severely [6, 7]. Despite the various surgical procedures proposed for the management of an insufficient bone union following OVF, optimal surgical procedures have not yet been clearly established. This may be because of the poor general condition and frequent instrumentation failure resulting from low bone quality in elderly patients. To treat these patients, a less invasive surgical approach in combination with more rigid fixation may be optimal [8], but some patients still require revision surgery because of progression of their kyphotic deformity, instrumentation failure, or both. Numerous comparative studies of surgical procedures have focused on clinical and radiographical outcomes, as well as the effect of bone fragility on the outcome of spinal surgery $[9,10]$. However, insights concerning the risk of postoperative mortality or morbidity are limited. Additionally, the effect of surgical therapy on survival after vertebral compression fractures remains controversial $[11,12]$. To establish an effective treatment strategy for patients with OVF, the postoperative mortality of patients who have undergone surgery for OVF, and the preoperative risk factors predictive of mortality after surgery, should be elucidated.

In the present study, we sought to evaluate the preoperative factors affecting the postoperative mortality of patients who underwent spinal surgery for an insufficient bone union following OVF and determine postoperative mortality.

\section{Methods}

\section{Patient cohort and surgery}

This study was a retrospective review of prospectively collected data. A total of 105 consecutive patients, with delayed osteoporotic thoracolumbar vertebral fractures, who underwent spinal surgery were studied (Table 1). Surgeries were conducted by three board certified spinal surgeons at a single institution between 2010 and 2018 . Initially, all patients with OVF were treated conservatively, and none of them had neurological deficits
Table 1 Preoperative characteristics and demographics of patients with OVF

\begin{tabular}{ll}
\hline Patients with OVF & $(\mathrm{N}=105)$ \\
\hline Age at the time of admission, $\mathrm{y}$ & $76.3 \pm 7.5$ \\
Gender, female/male, $\mathrm{n}$ & $65 / 40$ \\
$\mathrm{BMI}\left(\mathrm{kg} / \mathrm{m}^{2}\right)$ & $22.4 \pm 3.3$ \\
BMD (\%YAM) & $69.7 \pm 13.5$ \\
Follow-up duration, months & $28.3 \pm 31.8$ \\
Injured vertebral level (Th10-L2/L3-4) & $77 / 28$ \\
Type of Denis's classification (A/B/C) & $56 / 46 / 3$ \\
Intraoperative technique, $\mathbf{n}$ & \\
VP (HA) + PF & 49 \\
BKP & 18 \\
ADF + PF & 38
\end{tabular}

${ }^{\mathrm{a}}$ Mean \pm standard deviation, unless otherwise indicated $A D F$ anterior spinal decompression and fusion, BKP balloon kyphoplasty, BMI body mass index, $B M D$ bone mineral density, YAM young adult mean, $H A$ hydroxyapatite, OVF osteoporotic vertebral fractures, PF posterior fixation, $V P$ vertebroplasty

immediately after injury. Treatment options, including the use of a brace or drug therapy, or both, were selected by individual physicians based on their experience. Additionally, drug treatment for osteoporosis was started at the discretion of each physicians after visiting hospital. Surgical treatment was indicated for all 105 patients because they had progressive neurological deficits or continuous severe lower back pain caused by vertebral collapse. Indications for surgery in neurologically intact patients were persistent pain following 3 months of conservative treatment, presence of pseudoarthrosis \& progressive disability \& deformity.

Three surgical procedures were applied in the treatment of the patients in this study (Table 1). Forty-nine patients underwent posterior decompression and shortsegment fixation with vertebroplasty at the fractured level $(\mathrm{VP}(\mathrm{HA})+\mathrm{PF})$. After reduction, a 5 or $6-\mathrm{mm}$ diameter hole was made into the pedicles of the fractured vertebra bilaterally with a pedicle probe. A cavity extending to the anterior part of the vertebra was then created via both the pedicles of the fractured vertebra with elevation. Once the cannula reached the center of the vertebral body, under continuous fluoroscopic monitoring, hydroxyapatite (HA) blocks (Olympus) were pushed into the defect to completely fill the anterior region of the defect for vertebral reconstruction. This was combined with fixation of the two vertebrae above and one below with a pedicle screw. Another 18 patients received balloon kyphoplasty (BKP), and 38 patients underwent anterior spinal decompression and fusion, performed using a titanium cage and supplemented with posterior percutaneous pedicle screw fixation $(\mathrm{ADF}+\mathrm{PF})$. 


\section{Postoperative mortality}

The mean follow-up time for survival was $4.1 \pm 0.8$ years. The primary endpoint was death by the close of the study period, which ended in March 2019. Data were censored if the patient survived until the end of the study period. If a recent follow-up was not available from clinical records, patients were contacted by telephone to confirm their survival.

\section{Data collection}

For each patient who underwent spinal surgery for OVF, we searched clinical records and a laboratory database. Only measurements recorded 1-14 days before the date of surgery were used for preoperative measurements of body mass index (BMI), left ventricular ejection fraction (LVEF) measured using an echocardiogram, serum albumin, B-type natriuretic peptide (BNP), creatinine clearance $(\mathrm{CCr})$, and preoperative neurological impairment (according to a modified Frankel classification). Standardized bone mineral density (BMD, \% young adult men [YAM]) measurements at the lumbar spine (L2-L4) and the femoral neck were performed using a Lunar Prodigy dual-energy X-ray absorptiometry system (General Electric) at baseline. The American Society of Anesthesiologists (ASA) classification is a readily available and widely-accepted method for stratification of surgical patients according to their perioperative risk [13]. The visual analog scale (VAS) scores for the lumbar spine and leg were evaluated at the time of hospital admission and 1 year after surgery. Radiographic classification of burst fractures was based on the Denis classification using preoperative computed tomography [14].

\section{Statistical analyses}

Continuous variables were compared using unpaired $t$ tests and categorical variables were assessed using Fisher's exact tests for baseline characteristics between deceased patients and those who had survived for more than 2 years after surgery. Therefore, patients who had been followed for more than six months but less than two years were excluded in our analysis for Table 3 . Crude and adjusted hazard ratios (HRs) of mortality, using Cox proportional univariate and multivariate models, were calculated. We also made Kaplan-Meier estimates of all-cause mortality according to serum albumin levels as a possible risk factor of death in the Cox multivariate model. A log-rank test was used to assess the significance of differences between Kaplan-Meier estimates. All statistical calculations were conducted using Prism software, version 8.0 (Graph Pad Software, La Jolla, CA) and SAS statistical software, version 9.4 (SAS Institute, Cary, NC, USA). R statistical software (version 3.6.1, R Project for Statistical Computing, Vienna, Austria) was used to generate Kaplan-Meier estimates.
All reported $p$-values were two-sided and $p<0.05$ indicated statistical significance.

\section{Results}

Patient characteristics between those who died during the follow-up period and those who survived 2 years after surgery

Table 1 summarizes the characteristics of patients with OVF who underwent surgical procedures. Blood loss and surgical time for different surgical procedures were compared in Fig. 1. Estimated blood loss in patients treated with BKP was significantly lower than that in patients treated with $\mathrm{VP}(\mathrm{HA})+\mathrm{PF}$ or $\mathrm{ADF}+\mathrm{PF}$. There was no significant difference in estimated blood loss between patients treated with VP (HA) + PF and ADF + PF (Fig. 1a). Surgical time in patients treated with BKP was significantly shorter than that in patients treated with VP $(\mathrm{HA})+\mathrm{PF}$ or ADF + PF. Surgical time in patients treated with VP $(\mathrm{HA})+\mathrm{PF}$ was significantly shorter than that in patients treated with $\mathrm{ADF}+\mathrm{PF}$ (Fig. 1b). The VAS scores for both the lumbar spine and leg and modified Frankel classification were significantly improved one year after surgery compared to scores at the time of hospital admission (Table 2).

Two years after surgery, 19/75 patients (15\%) with OVF had died. Table 3 summarizes the preoperative baseline characteristics of the patients with OVF who died compared with those who were still alive two years after surgery. There were no significant differences in the age, BMI, LVEF (\%), BNP level, $\mathrm{CCr}$, or BMD, follow-up period, time from original injury to surgery, distribution of preoperative fracture type based on Denis's classification, or estimated blood loss and operative time between groups. A significant difference in mortality among the three surgical procedures was not found (Table 3). In contrast, the ratio of males-tofemales was significantly higher among the patients with OVF who died than for those who were still alive. Additionally, preoperative serum albumin levels and $\mathrm{CCr}$ were significantly lower in patients who died than in those who were still alive (Table 3).

\section{Preoperative factors affecting the long-term survival of the patients who underwent spinal surgery for an insufficient bone union following OVF}

The presurgical hazard ratios (95\% confidence interval) for mortality associated with patient characteristics are summarized in Table 4. According to a past report, hypoalbuminemia was defined as serum albumin $\leq 3.5 \mathrm{~g} / \mathrm{dL}$ [15]. The univariate analysis showed that male gender, serum albumin $<3.5 \mathrm{~g} / \mathrm{dl}, \mathrm{CCr}<60 \mathrm{mg} / \mathrm{dl}$, and an ASA classificat0ion $\geq 3$ were significant risk factors for postoperative mortality (Table 4). The multivariate analysis revealed that hypoalbuminemia was the only significant 

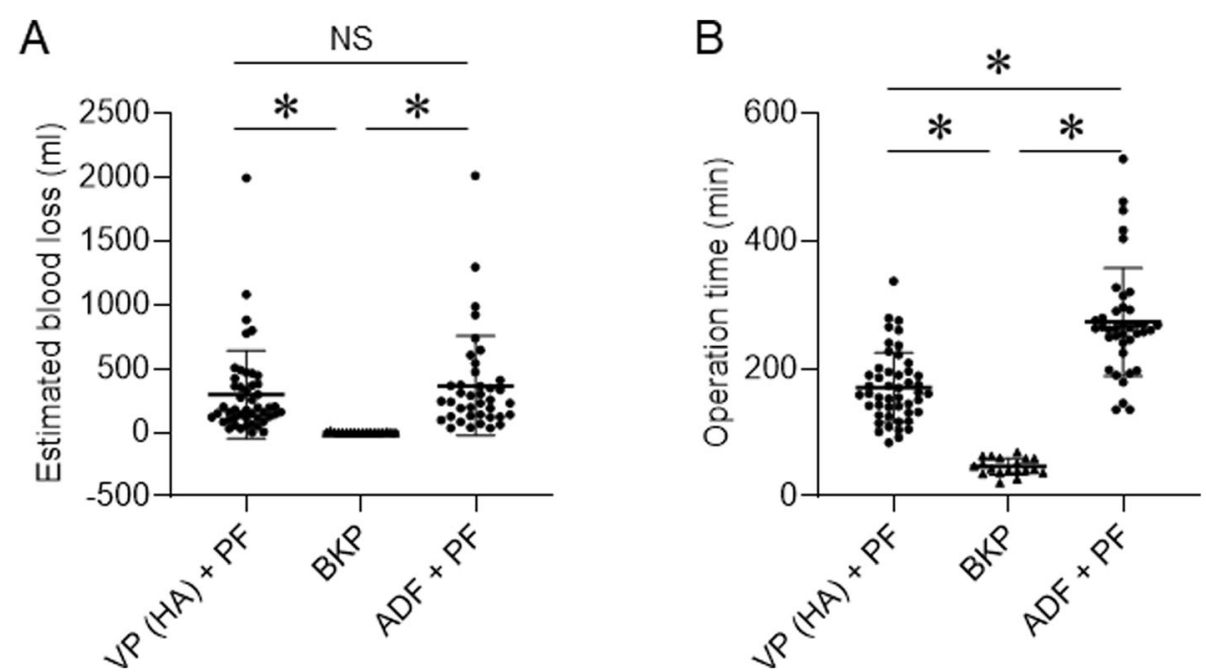

Fig. 1 Comparisons of blood loss (a) and surgical time (b) among surgical procedures. ADF, anterior spinal decompression and fusion; BKP, balloon kyphoplasty; HA, hydroxyapatite; PF, posterior fixation; VP, vertebroplasty. ${ }^{*} P<0.05$; NS = not significant. Data were analyzed using the unpaired t-test

risk factor for long-term postoperative mortality of OVF (adjusted hazard ratio was 3.37; $p=0.014$; Table 4).

\section{Effect of preoperative serum albumin level on postoperative mortality}

Based on the threshold values defined, there were two preoperative serum albumin levels, $\leq 3.5 \mathrm{~g} / \mathrm{dL}$ and $>3.5 \mathrm{~g} /$ dL [14]. Thirty-eight patients (36.2\%) had hypoalbuminemia. The estimated risk of mortality at the final followup, using the Kaplan-Meier method, was significantly greater in patients with preoperative serum albumin $\leq 3.5 \mathrm{~g} / \mathrm{dL}$ than in those with a serum albumin $>3.5 \mathrm{~g} / \mathrm{dL}$ $(p<0.0001$ for log-rank test; Fig. 2).

\section{Discussion}

Numerous studies have found an association between OVF and increased mortality, with pulmonary and cardiovascular-related deaths suggested as being explanatory factors for the excess mortality [14-16]. A past study showed a 2- to 8-times increased risk of agematched mortality following OVF [16]. Surgical intervention is often recommended for patients who have an insufficient bony union of OVF, persistent back pain, and/or neurological deficits [17]. Recently, interest has increased in the mortality and morbidity of patients who undergo spinal surgery $[18,19]$. Additionally, numerous reports have surfaced for comparative studies of surgical procedures for OVF; these have focused on surgical invasiveness and complications [20]. By contrast, the postoperative outcome of pain and survival of patients with an insufficient bony union after OVF surgery remains largely unknown. Although the present study showed that the VAS scores for both the lumbar spine and leg were significantly improved one year after surgery compared to scores at the time of hospital admission, those scores may not be meaningful clinically. A recent study indicated that instrumented fusion surgery for lumbar trauma in the elderly is associated not only with increased morbidity, but also with reduced mortality [21]. Therefore, we sought to elucidate the preoperative risk factors which may predict postoperative mortality. Interestingly, our study indicated no significant differences in postoperative mortality among the 3 different surgical procedures assessed for OVF.

The association between malnutrition and mortality risk has been shown in patients with hip fractures $[22$,

Table 2 Pre- and postoperative patient VAS scores (lumbar and leg) and Modified Frankel classification

\begin{tabular}{llll}
\hline & Preoperative & 1 year after surgery & $p$-value \\
\hline VAS score (lumbar) & $7.4 \pm 3.4$ & $5.8 \pm 3.8$ & $<0.05^{*}$ \\
VAS score (leg) & $6.7 \pm 2.8$ & $3.4 \pm 2.1$ & $<0.05^{*}$ \\
Modified Frankel classification (A/B/C/D/E) & $0 / 0 / 44 / 39 / 22$ & $0 / 0 / 28 / 42 / 31$ & $<0.05^{\dagger}$ \\
\hline
\end{tabular}

*Mean \pm standard deviation, unless otherwise indicated

${ }^{*} P<0.05$ in the comparison between groups

${ }^{\dagger} p$ value for Fisher's exact test for Modified Frankel classification $C$ versus $D$ or $E$

VAS visual analog scale 
Table 3 Factors associated with subsequent survival/mortality in patients who survived more than 2 years after surgery

\begin{tabular}{|c|c|c|c|c|}
\hline Characteristic & Died $(n=19)$ & Survived $(n=56)$ & $p$-value ${ }^{\dagger}$ & Power \\
\hline Male gender, n (\%) & $11(57.9)$ & $16(28.6)$ & $0.029^{*}$ & 0.48 \\
\hline Age, years & $79.1(7.6)$ & $75.6(8.0)$ & 0.10 & 0.38 \\
\hline $\mathrm{BMI}, \mathrm{kg} / \mathrm{m}^{2}$ & $21.3(3.1)$ & $22.5(3.0)$ & 0.15 & 0.31 \\
\hline LVEF, \% & $70.3(9.6)$ & $71.9(14.1)$ & 0.65 & 0.078 \\
\hline Serum albumin, g/dL & $3.4(0.5)$ & $3.9(0.5)$ & $0.0016^{*}$ & 0.96 \\
\hline BNP, pg/mL & $45.3(36.4)$ & $44.9(47.2)$ & 0.98 & 0.050 \\
\hline $\mathrm{CCr}, \mathrm{mL} / \mathrm{min}$ & $49.9(20.1)$ & $63.1(21.6)$ & $0.021^{*}$ & 0.65 \\
\hline BMD, \%YAM & $63.4(14.0)$ & $66.8(13.4)$ & 0.47 & 0.15 \\
\hline Follow-up, months & $57.1(21.2)$ & $66.4(25.3)$ & 0.13 & 0.32 \\
\hline Time from original injury to surgery, months & $4.4(2.1)$ & $4.6(0.49)$ & 0.21 & 0.090 \\
\hline Type of Denis's classification (A/B.C) & $12 / 7$ & $34 / 21$ & 0.72 & \\
\hline Surgical procedures & & & 0.087 & \\
\hline$V P(H A)+P F$ & $11(57.9)$ & $27(48.2)$ & & \\
\hline BKP & $2(10.5)$ & $16(28.6)$ & & \\
\hline $\mathrm{ADF}+\mathrm{PF}$ & $6(31.6)$ & $13(23.2)$ & & \\
\hline ASA classification $\geq 3$ & $7(36.8)$ & $6(10.7)$ & $0.016^{*}$ & \\
\hline \multicolumn{5}{|l|}{ Modified Frankel classification } \\
\hline$C$ versus $\mathrm{D}$ or $\mathrm{E}$ & $8(47.1)$ & $21(38.2)$ & 0.58 & \\
\hline Estimated blood loss, ml & $168(155)$ & $335(499)$ & 0.11 & \\
\hline Operative time, $\min$ & $162(98.9)$ & 201 (114.3) & 0.13 & \\
\hline
\end{tabular}

${ }^{\dagger} p$ value for Fisher's exact test or Student's $t$ test

$* \mathrm{P}<0.05$ in the comparison between groups

Variables are presented as mean (standard deviation) unless noted otherwise

$A D F$ anterior spinal decompression and fusion, $A S A$ American Society of Anesthesiologists, $B M D$ bone mass density, BKP balloon kyphoplasty, $n$ number in group, $B M I$ body mass index, BNP B-type natriuretic peptide, $C C r$ creatinine clearance, HA hydroxyapatite, $L V E F$ left ventricular ejection fraction, $P F$ posterior fixation, $V P$ vertebroplasty, YAM young adult male

23]. Additionally, a recent study indicated that serum albumin levels predict which patients are at increased risk for minor or major complications, or mortality, following surgical management of acute osteoporotic vertebral compression fractures [24]. We presumed that patients with long-term post-injury OVF may be at increased risk of malnutrition due to ongoing pain compared to acute fractures. Serum albumin is a well-known and important marker of preoperative nutritional status. Low levels of serum albumin can be prognostic by influencing organ vascularization and may hinder antibiotic therapy, prolong inflammation, and prompt intravascular coagulation [25]. Numerous oncology studies have established a preoperative serum albumin level of $\leq 3.5 \mathrm{~g} / \mathrm{dL}$ as the cut-off value for risk of poor overall survival [26, 27].

According to past studies, preoperative serum albumin levels were significantly lower in the patients with OVF who died, than in those who remained alive. The present study also showed a significant association between a low preoperative serum albumin level of $\leq 3.5 \mathrm{~g} / \mathrm{dL}$, and

Table 4 Pre-surgery hazard ratios $(95 \% \mathrm{Cl})$ of mortality based on patient characteristics $(\mathrm{N}=105)$

\begin{tabular}{lllll}
\hline Explanatory variable & Crude & $p$-value & Adjusted HR $^{+}$ & $p_{\text {-value }}$ \\
\hline Male vs female gender & $2.74(1.17,6.41)$ & 0.021 & $1.82(0.76,4.40)$ & 0.18 \\
BMI $\geq 25$ vs $18.5-24.9 \mathrm{~kg} / \mathrm{m}^{2} \mathrm{BMI} \geq 25$ vs. $18.5-24.9 \mathrm{~kg} / \mathrm{m}^{2}$ & $1.45(0.41,5.09)$ & 0.56 & $1.67(0.44,6.32)$ & 0.45 \\
$\mathrm{BMI}<18.5 \mathrm{vs} 18.5-24.9 \mathrm{~kg} / \mathrm{m}^{2} \mathrm{BMl}<18.5 \mathrm{vs} .18 .5-24.9 \mathrm{~kg} / \mathrm{m}^{2}$ & $2.78(0.99,7.81)$ & 0.052 & $2.81(0.96,8.25)$ & 0.061 \\
Serum albumin $<3.5 \mathrm{~g} / \mathrm{dL}$ & $4.99(2.00,12.43)$ & 0.0006 & $3.37(1.28,8.89)$ & 0.014 \\
CCr $<60 \mathrm{mg} / \mathrm{dL}$ & $3.40(1.15,10.06)$ & 0.027 & $1.96(0.63,6.05)$ & 0.25 \\
ASA physical status classification $\geq 3$ & $3.93(1.68,9.21)$ & 0.0017 & $2.36(0.93,6.01)$ & 0.072 \\
\hline
\end{tabular}

${ }^{\dagger}$ Explanatory variables were selected using $p<0.2$ in the univariate analysis for crude hazard ratios. All of the variance inflation factors in the multivariate model for the calculation of adjusted hazard ratios were $<1.22$, indicating there was no multicollinearity ASA American Society of Anesthesiologists, BMI body mass index, $\mathrm{CCr}$ creatinine clearance, $\mathrm{Cl}$ confidence interval, $\mathrm{HR}$ hazard ratio 


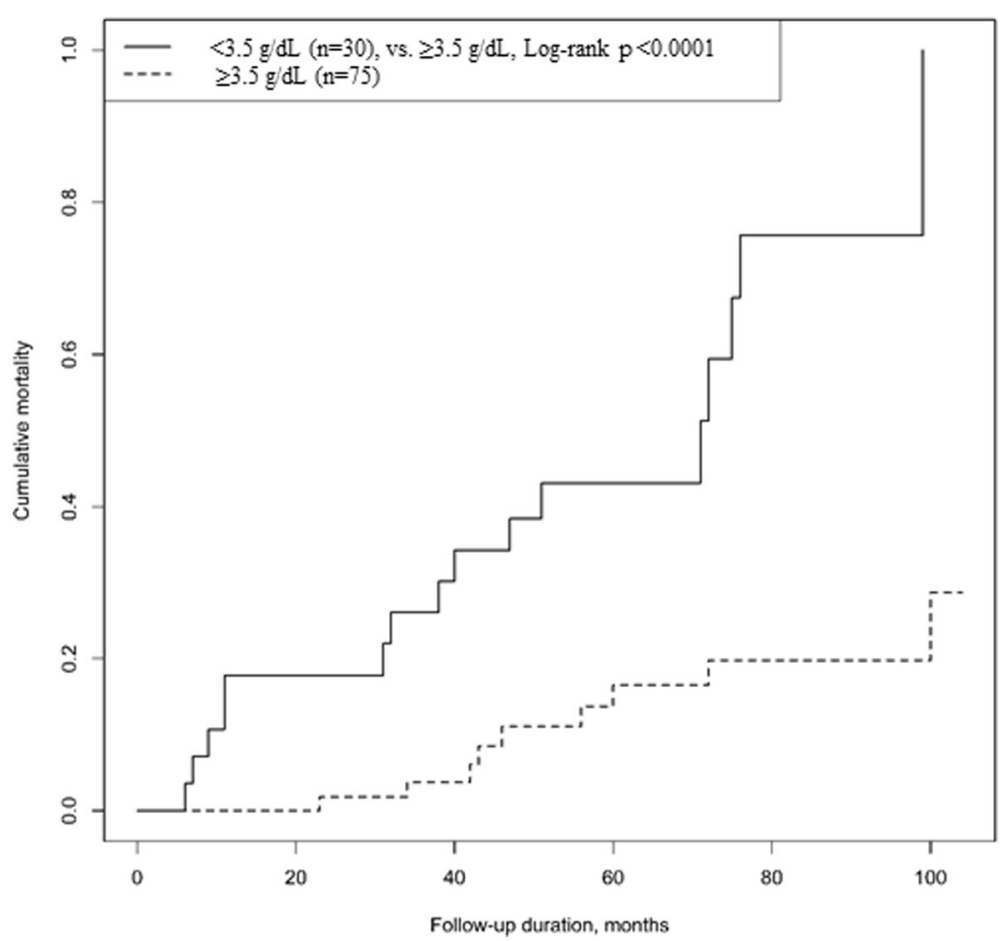

Fig. 2 Overall survival comparison based on preoperative serum albumin levels (dashed line, $\leq 3.5 \mathrm{~g} / \mathrm{dL}$; solid line, $>3.5 \mathrm{~g} / \mathrm{dL}$ ) using the Kaplan-Meier method

a reduction in overall survival for patients undergoing surgery for an insufficient union of OVF.

This study has some limitations. First, this study was retrospective and had a small sample size and duration of follow-up; a prospective study and a longer follow-up time would have been preferable. Second, we do not know whether surgical therapy or a difference in surgical techniques had an impact on the patients' prognosis because an individual spine surgeon might decide on surgery depending on the patient's general condition. Further study is needed to clarify the strategy for selecting surgical procedures, and these studies should include OVF patients treated with conservative therapy. Third, the differences between patients with injuries at different spinal levels should be investigated with a larger sample size. However, the present study clearly shows that hypoalbuminemia is particularly important among the many predicted risk factors for increased postoperative mortality following OVF surgery. This result suggests that designing a treatment strategy that takes into consideration indications and optimal timing for OVF surgery may have clinical significance. Based on the present study, we propose that if OVF patients are found to have poor nutrition by preoperative examination, attention to nutrition should be paid postoperatively, and/or less invasive procedures may be considered. Additionally, efforts should be made to improve nutritional status before surgery. Further studies are needed to investigate the effects on postoperative mortality of improving nutritional status before surgery.

\section{Conclusion}

Hypoalbuminemia was associated with increased postoperative mortality following OVF surgery.

\section{Abbreviations}

OVF: Osteoporotic vertebral fractures; LSS: Lumbar spinal canal stenosis; BMI: Body mass index; LVEF: Left ventricular ejection fraction; BNP: B-type natriuretic peptide; CCr: level, Creatinine clearance; BMD: Bone mass density; ASA: The American Society of Anesthesiologists

\section{Acknowledgements}

None.

\section{Authors' contributions}

TO analyzed and interpreted the patient data and was a major contributor to writing the manuscript. HY developed the study design. KK performed the statistical analyses. TN and OK collected patient data. HH was an editorial supervisor for this study. All authors read and approved the final manuscript.

Funding

There was no funding to support this research.

Availability of data and materials

The datasets used and/or analyzed during the current study are available from the corresponding author on reasonable request. 


\section{Ethics approval and consent to participate}

This study was approved by the institutional review board Ethics Committee of the University of Yamanashi School of Medicine, Chairperson Zentarou Yamagata (Application number 1183).

\section{Consent for publication}

Not applicable.

\section{Competing interests}

The first author Tetsuro Ohba is an Editorial Board member for the journal.

\section{Author details}

'Department of Orthopaedic Surgery, University of Yamanashi, 1110 Shimokato, Chuo, Yamanashi 409-3898, Japan. ${ }^{2}$ Department of Health Sciences, University of Yamanashi, Yamanashi, Japan.

Received: 17 November 2019 Accepted: 3 August 2020

Published online: 10 August 2020

\section{References}

1. Lee YL, Yip KM. The osteoporotic spine. Clin Orthop Relat Res. 1996;323: $91-7$.

2. Center JR, Nguyen TV, Schneider D, Sambrook PN, Eisman JA. Mortality after all major types of osteoporotic fracture in men and women: an observational study. Lancet. 1999;353(9156):878-82.

3. Lau E, Ong K, Kurtz S, Schmier J, Edidin A. Mortality following the diagnosis of a vertebral compression fracture in the Medicare population. J Bone Joint Surg Am. 2008;90(7):1479-86.

4. Katsu M, Ohba T, Ebata S, Haro H. Comparative study of the paraspinal muscles after OVF between the insufficient union and sufficient union using MRI. BMC Musculoskelet Disord. 2018;19(1):143.

5. Hasegawa K, Homma T, Uchiyama S, Takahashi H. Vertebral pseudarthrosis in the osteoporotic spine. Spine (Phila Pa 1976). 1998;23(20):2201-6.

6. Tsujio T, Nakamura H, Terai H, Hoshino M, Namikawa T, Matsumura A, Kato M, Suzuki A, Takayama K, Fukushima W, et al. Characteristic radiographic or magnetic resonance images of fresh osteoporotic vertebral fractures predicting potential risk for nonunion: a prospective multicenter study. Spine (Phila Pa 1976). 2011;36(15):1229-35.

7. Carlson BC, Robinson WA, Wanderman NR, Sebastian AS, Nassr A, Freedman BA, Anderson PA. A review and clinical perspective of the impact of osteoporosis on the spine. Geriatric Orthop Surg Rehabil. 2019;10: 2151459319861591.

8. Vanni D, Pantalone A, Magliani V, Salini V, Berjano P. Corpectomy and expandable cage replacement versus third generation percutaneous augmentation system in case of vertebra plana: rationale and recommendations.J Spine Surg (Hong Kong). 2017:3(3):379-86.

9. Sudo H, Ito M, Kaneda K, Abumi K, Kotani Y, Nagahama K, Minami A, Iwasaki N. Anterior decompression and strut graft versus posterior decompression and pedicle screw fixation with vertebroplasty for osteoporotic thoracolumbar vertebral collapse with neurologic deficits. Spine J. 2013; 13(12):1726-32.

10. Uchida K, Nakajima H, Yayama T, Miyazaki T, Hirai T, Kobayashi S, Chen K, Guerrero AR, Baba H. Vertebroplasty-augmented short-segment posterio fixation of osteoporotic vertebral collapse with neurological deficit in the thoracolumbar spine: comparisons with posterior surgery without vertebroplasty and anterior surgery. J Neurosurg Spine. 2010;13(5):612-21.

11. Lavelle WF, Khaleel MA, Cheney R, Demers E, Carl AL. Effect of kyphoplasty on survival after vertebral compression fractures. Spine J. 2008;8(5):763-9.

12. Edidin AA, Ong KL, Lau E, Kurtz SM. Morbidity and mortality after vertebral fractures: comparison of vertebral augmentation and nonoperative Management in the Medicare Population. Spine (Phila Pa 1976). 2015;40(15): $1228-41$.

13. Reid BC, Alberg AJ, Klassen AC, Koch WM, Samet JM. The American Society of Anesthesiologists' class as a comorbidity index in a cohort of head and neck cancer surgical patients. Head Neck. 2001;23(11):985-94.

14. Denis $\mathrm{F}$. The three column spine and its significance in the classification of acute thoracolumbar spinal injuries. Spine (Phila Pa 1976). 1983;8(8):817-31

15. Gom I, Fukushima H, Shiraki M, Miwa Y, Ando T, Takai K, Moriwaki $H$. Relationship between serum albumin level and aging in communitydwelling self-supported elderly population. J Nutr Sci Vitaminol (Tokyo). 2007:53(1):37-42.
16. Schousboe JT. Epidemiology of vertebral fractures. J Clin Densitometry. 2016:19(1):8-22

17. Kashii M, Yamazaki R, Yamashita T, Okuda S, Fujimori T, Nagamoto Y, Tamura Y, Oda T, Ohwada T, Yoshikawa H, et al. Surgical treatment for osteoporotic vertebral collapse with neurological deficits: retrospective comparative study of three procedures--anterior surgery versus posterior spinal shorting osteotomy versus posterior spinal fusion using vertebroplasty. Eur Spine J. 2013;22(7):1633-42.

18. Street JT, Lenehan BJ, DiPaola CP, Boyd MD, Kwon BK, Paquette SJ, Dvorak MF, Rampersaud YR, Fisher CG. Morbidity and mortality of major adult spinal surgery. A prospective cohort analysis of 942 consecutive patients. Spine J. 2012;12(1):22-34.

19. Fu KM, Smith JS, Polly DW Jr, Perra JH, Sansur CA, Berven SH, Broadstone PA, Choma TJ, Goytan MJ, Noordeen HH, et al. Morbidity and mortality in the surgical treatment of 10,329 adults with degenerative lumbar stenosis. J Neurosurg Spine. 2010;12(5):443-6.

20. Ohba T, Ebata S, Clinton D, Koyama K, Haro H. Instability of treated vertebrae after balloon kyphoplasty causing paraparesis in osteoporotic vertebral compression fracture: a report of two cases. Eur Spine J. 2013: 22(Suppl 3):S341-5.

21. Winkler EA, Yue JK, Birk H, Robinson CK, Manley GT, Dhall SS, Tarapore PE. Perioperative morbidity and mortality after lumbar trauma in the elderly. Neurosurg Focus. 2015;39(4):E2.

22. Ko Y, Baek SH, Ha YC. Predictive factors associated with mortality in Korean elderly patients with hip fractures. J Orthop Surg (Hong Kong). 2019;27(2): 2309499019847848

23. Li S, Zhang J, Zheng H, Wang X, Liu Z, Sun T. Prognostic role of serum albumin, Total lymphocyte count, and mini nutritional assessment on outcomes after geriatric hip fracture surgery: a meta-analysis and systematic review. J Arthroplast. 2019;34(6):1287-96.

24. Gupta A, Upadhyaya S, Cha T, Schwab J, Bono C, Hershman S. Serum albumin levels predict which patients are at increased risk for complications following surgical management of acute osteoporotic vertebral compression fractures. Spine J. 2019;19(11):1796-802.

25. Fuhrman MP, Charney P, Mueller CM. Hepatic proteins and nutrition assessment. J Am Diet Assoc. 2004;104(8):1258-64.

26. Chandrasinghe PC, Ediriweera DS, Kumarage SK, Deen Kl. Pre-operative hypoalbuminaemia predicts poor overall survival in rectal cancer: a retrospective cohort analysis. BMC Clin Pathol. 2013;13:12.

27. Montomoli J, Erichsen R, Antonsen S, Nilsson T, Sorensen HT. Impact of preoperative serum albumin on 30-day mortality following surgery for colorectal cancer: a population-based cohort study. BMJ Open Gastroenterol. 2015;2(1):e000047.

\section{Publisher's Note}

Springer Nature remains neutral with regard to jurisdictional claims in published maps and institutional affiliations.

Ready to submit your research? Choose BMC and benefit from:

- fast, convenient online submission

- thorough peer review by experienced researchers in your field

- rapid publication on acceptance

- support for research data, including large and complex data types

- gold Open Access which fosters wider collaboration and increased citations

- maximum visibility for your research: over $100 \mathrm{M}$ website views per year

At $\mathrm{BMC}$, research is always in progress.

Learn more biomedcentral.com/submissions 